\title{
Historical hackathon for schoolchildren, students and practicing teachers as an educational platform of a new format
}

\author{
I.I. Makarova ${ }^{1 *}$, D.V. Ratnikova ${ }^{2}$, and P.E. Pobezhimova ${ }^{3}$ \\ ${ }^{1}$ Altai State Pedagogical University, Barnaul, Russia \\ ${ }^{2}$ Altai State Pedagogical University, Barnaul, Russia \\ ${ }^{3}$ Altai State Pedagogical University, Barnaul, Russia
}

\begin{abstract}
A significant problem of continuous self-education remains the organization of educational platforms of a new format that would contribute to the formation and development of hard and soft skills. The article discusses innovative teaching methods, which include the historical hackathon for schoolchildren, students and practicing teachers. The hackathon format is presented as an effective tool for a complex combination of creative potential, knowledge and skills in the field of historical sciences, IT technologies and historical identity.
\end{abstract}

\section{A problem statement}

Analysis of the practice of the volunteer and tutor movement, questioning and interviewing students demonstrate a pronounced need for young people to preserve historical memory, study genealogies, the history of working dynasties, the desire to participate in historical projects and initiatives, as well as pride in the military and labor exploits of older generations, which, in turn, dictates the need to create and develop new forms of involving the younger generation in civil-patriotic socially significant activities.

According to the Concept of long-term socio-economic development of the Russian Federation, for the period up to 2020, the involvement of young people in social practice and their informing about the potential opportunities for self-development, support for scientific, creative and entrepreneurial activity of young people is one of the priority directions of state policy of the Russian Federation [1]. The national project "Education", the implementation of which began in 2019, is no less important.

In the framework of the national project "Education" there are a number of federal projects that are designed to solve such practical tasks as:

- formation of an effective system for identifying, supporting and developing the abilities and talents of children and youth, based on the principles of justice, universality and aimed at self-determination and professional orientation of all students;

- introduction of a national system of professional development of teachers, covering at least 50 percent of teachers in general education organizations;

${ }^{*}$ Corresponding author: ipcs-profped@yandex.ru 
- modernization of vocational education, including through the introduction of adaptive, practice-oriented and flexible educational programs [2].

The sources of financial support for the implementation of the national project "Education", provided until 2024, are the federal budget (723.3 milliard rubles), the budgets of the constituent entities of the Russian Federation (45.7 milliard rubles), extra-budgetary sources (15.4 milliard rubles) [2].

In the process of discussion and adoption of the national project "Education", it was assumed that by the end of 2020, a national system of teacher growth of teachers will be introduced by $100 \%, 70 \%$ of teachers under the age of 35 will be involved in various forms of support and support in the first three years of work, that is, by the end of 2024. The support and maintenance of professional pedagogical growth, the formation and development of relevant professional competencies hade a positive effect on the involvement of schoolchildren and students in civil-patriotic socially significant activities [2].

Nevertheless, at present there is a low rate of digitalization of education, the absence of educational platforms for joint creativity of schoolchildren, students and practicing teachers with IT specialists.

This is evidenced by the content and results of the Barnaul-2019 hackathon, where among 28 prototypes presented by the participants to the jury and experts, only 3 were devoted to solving educational problems and only one of them was to the study of history [3].

Pedagogical universities are initially focused on the formation of professional competencies that allow them to design programs of academic disciplines and special courses, to develop methodological materials, assessment tools for the implementation of basic and additional educational programs (including using information and communication technologies), to build individual educational routes, to use the most effective forms, methods and technologies for organizing joint and individual educational and extracurricular activities of students, apply modern scientific knowledge and the results of scientific research in the process of pedagogical design. However, academic disciplines (Fundamentals of information culture, Information and communication technologies in the educational process, Research and project activities at school, Fundamentals of research work), which form research and IT competencies so important for a young teacher, are not included in the mandatory part of the curriculum of pedagogical universities. Most often, these are optional disciplines. Consequently, young specialists - teachers in remote rural schools are faced not only with the problems of poor Internet access, weak material and technical base of educational organizations, but also with the lack of skills and abilities necessary in modern conditions. Thus, the importance of the system of continuous selfeducation for practicing teachers as effective professionals is vital.

The organization of educational platforms that would contribute to the formation and development of hard and soft skills remains a significant problem of continuous selfeducation. Therefore, one of the many tasks of pedagogical universities at present is the competitive support of young teachers in their desire to actively develop in the profession.

Today, teaching staff in higher education increasingly strives to strengthen the link between teaching and research, which fosters a culture that allows schoolchildren, students and young teachers to take a lifelong research approach to their development.

Such active learning is associated with an increase in the research competence of students. Nevertheless, the questions about the methods of acquainting schoolchildren, students, young teachers with the world of research, about helping them to achieve success have not been sufficiently studied.

An effective and interesting form of educational platforms that allow developing and improving the competencies of schoolchildren, students and young teachers related to 
project, research and IT activities within the modern educational space is a hackathon - a forum for developers, during which specialists from different fields of knowledge work together to solve any problem for a certain time.

On the basis of AltSPU in 2019, the project Historical hackathon „My Russia” was implemented [4]. The hackathon can reasonably be considered a new type of educational platform. The participation of youth teams of schoolchildren, students and young teachers in it allows you to immerse yourself in the historical and local history topics based on love and respect for the small Motherland, understanding the value of the labor, moral and military feat of their ancestors and contemporaries, preserving historical memory, the continuity of spiritual values and civil ideals. The value of the idea and its relevance for students is that they themselves become bearers of historical memory, from the study of their small Motherland to the comprehension of the national idea.

Participation in such a unique process is a full-fledged opportunity for a startup for both learning youth and practicing teachers, increasing their own hardskills and softskills [5].

The team of the hackathon project of the history department of AltSPU, having taken part in the 2018-2019 academic year in various forms and content of youth competitions of ideas and startups, came to the conclusion that the innovative creative potential of schoolchildren, students, young teachers is not fully used to create modern web -services on history and local history for educational or social purposes. It was decided to organize a similar competition on the basis of local history studies. The historical hackathon "My Russia" involved three categories of participants: schoolchildren, students and young teachers worked simultaneously. To ensure the high quality and efficiency of the event, the necessary mobile presentation equipment was purchased, and a stable Internet connection was provided on the basis of the educational platform.

The hackathon was held in several stages:

- information campaign, including the distribution of letters of invitation and the Regulations on the hackathon "My Russia";

- selection by the expert commission of projects and ideas for participation in expert sessions and presentation forum;

- the main stage - an offsite two-day educational platform, including a pitch of ideas, an expert session, tutoring for teams and project defense;

- the final stage - rewarding the best participating teams, placing the created educational resources on a special portal. This made it possible to prolong the project, translate it into the plane of practical application in school history education and ensure broad public awareness of the results and further viability of the youth project.

Since digitalization is one of the key areas of interest for young people, the hackathon format seems to us to be an effective tool for a complex combination of creative potential, knowledge and skills in the field of historical sciences, IT technologies and historical identity. The idea is based on the search for common interests of young participants, a project approach, work in teams, the development of supra-professional skills and, as a result, the creation of new educational products, web applications and virtual tours, the development of military tactical games, maps, applications and services (for example, for junior detachments).

\subsection{The objective of the work}

Today it is generally accepted that success in professional activity depends on the level of professionalism of a person endowed with a number of key qualities. S.N. Batsunov refers to such qualities: understanding of oneself in the profession, knowledge of job responsibilities, perseverance and more. The author believes that a good specialist today is a public specialist who can mobile and integratively choose a productive way of interacting 
with the environment, consisting of many elements, the dynamism, change and transformation of which depend on the situation of immersion in it [5].

For a very long time, a young teacher, just like a trainee teacher, has a fear of doing something wrong, differently than others, the environment of mentors dictates the principles of leadership that are convenient for them, the dynamism of change is an obstacle to objectivity. Therefore, the main goal of the educational institution is to create the necessary and full-fledged conditions for the personal development of the student and the formation of his creative cognitive activity [6].

It is often impossible to achieve success without the proper soft skills. D. Goleman writes that a person's effectiveness in professional activity directly depends on the level of development of his "soft" skills, which, in his opinion, distinguish "successful specialists from unsuccessful ones" [7,8].

The term "soft skills" has a number of definitions: these are "personal qualities that allow you to effectively and harmoniously interact with other people" [9]; human qualities, without which even the best professional will not be able to achieve a good result ...", "skills acquired through additional education and personal life experience and used for their own development in professional activities", "social skills that make it possible to establish interaction with different age groups categories of people", "social and psychological skills: communicative leadership, team, public and others ", etc. [5].

The introduction of the Federal State Educational Standard entailed a change in the requirements for the process and learning outcomes. The main principle for assessing the quality of modern education began to be considered not a set of knowledge, but formed competencies that help to use this knowledge in practice. In the learning process, where the practical component is given special attention, the student acts actively, is involved in the process of independent search and "discovery" of new knowledge, solves problems of a problematic nature, plunging into the studied problem [10].

There is still no consensus on the use of innovative methods in the field of teacher education. In general, in relation to the pedagogical process, innovation is the introduction of something new into the goals, content, methods and forms of teaching and upbringing [11]. There are a number of methods: problem, game technologies, technologies of group and collective activities, methods of situation analysis, the method of projects and others, which are currently the most relevant in the process of forming subject and supra-subject competencies. The use of such innovative methods allows you to build an effective educational process [12].

Today, the emphasis in the educational environment of a pedagogical university is placed on design and research activities. According to E.F. Zeer, "the main factor in achieving the heights of professionalism is self-actualization, based on the realization of one's personal and professional potential" [13].

Examples of practical implementation of the application of innovative methods are virtual excursions and museums, interactive maps, manuals, etc., which are based on the solution of creative search problems $[14,15]$.

In this regard, V.V. Pshenichnaya sees the hackathon as one of the ways to implement project-based learning, during which passionate people come together, form work teams to solve problems, and collaborate to find innovative solutions from scratch. At the end of the hackathon, solutions are presented and evaluated. The assessment takes into account the viability, practical significance and "wow factor" of the solution [16].

According to O.F. Bryksina and E.P. Krupoderova, the application of the hackathon in education can help bridge the gap between theoretical knowledge and the practice of its application through innovative methods of obtaining and sharing knowledge. The authors believe that it is possible to help schoolchildren, students, and young teachers in their continuous development by teaching them how to acquire and create knowledge through 
independent research, expand their knowledge in the field of science and equip them with practical skills, increasing motivation and cognitive interest in learning [17].

S.A. Chernov emphasizes that "knowledge is formed and develops in the process of integration of various information flows and its interpretation" [18].

\section{Materials and the results of the research}

The main goal: to create an educational platform of a new format for the maximum involvement of schoolchildren, students and practicing teachers in the formation of personal subjective experience of understanding the national idea and value attitude to key historical facts using digital technologies.

Tasks:

1. Creation of an educational platform of a new type and providing it with full-fledged resources for interaction of schoolchildren, students, young teachers with representatives of IT companies, experts in the field of science and history education.

2. Conducting a wide information campaign to form a set of creative concepts and projects in the development of educational web resources of historical and local history.

3. Formation of an expert community from representatives of the Ministry of Education and Science, the Ministry of Digital Development and Communications of the Altai Region, the administration of the Altai State Pedagogical University, the children's technopark "Quantorium.22", practicing history teachers of the highest category, historiansresearchers, local history experts, IT companies to evaluate ideas and projects, the competitiveness of teams participating in the face-to-face stage of the "My Russia" hackathon.

4. Teaching pupils, students, young teachers new knowledge, skills and abilities necessary for the formation of competencies in the field of IT-technologies (creation of web resources, projects, products) with the aim of their further implementation in educational and creative practice in history and local history.

5. Conducting competitive events and presentations aimed at selecting the best ideas and projects.

6. Creation of a platform for placing digital resources, historical software products developed by the participants within the framework of the event.

The main content of the preparatory stage for the historical hackathon "My Russia" was the identification by schoolchildren, students, young teachers of key issues in the field of educational historical research, the organization of design and research activities, the use of IT technologies in lesson and extracurricular work on history. During the preparatory stage, the most significant problems were identified:

- determination of the gap between the formed historical knowledge and practical actions in various areas of the educational process: patriotic, local history and search direction; IT sphere; basics of project activities;

- the formation of critical thinking skills necessary for an effective assessment of the proposed ideas;

- revealing the value of interdisciplinary and multicultural approaches to global knowledge;

- the creation of ideas about the use of specific methodological tools in the conduct of historical and regional studies.

In preparation for the hackathon, schoolchildren, students, young teachers formed working teams of three people (competent in the field of history, project activities and the IT sphere). Their first task was to present a product idea for their own project.

The preparation of schoolchildren, students, young teachers for the hackathon was based on the principle of participation, which implies inclusion in the educational process. 
Each of the team members at a certain stage of work on the project got the opportunity to become a leader or a person who makes the final decision. In the process of joint activities, the participants of the hackathon formed a positive personal subjective experience in the use of IT technology, organization and conduct of historical research of local lore, in interdisciplinary cooperation. This allowed them to be focused on achieving a full-fledged result of project activities.

The result of the preparatory stage was the independent immersion of each team in the process of creating their own project.

As part of the main stage, a key event was organized - a 48-hour face-to-face platform for the refinement, creation and protection of finished project products. The hackathon participants presented 30 projects that were closely scrutinized and evaluated by a competent pool of 15 experts in the field of patriotic, local history and search directions, ITsphere and the basics of project activities. The projects were evaluated according to the following criteria:

- the level of practical implementation;

- originality of the idea, lack of analogues;

- mass audience - a consumer of a digital product;

- the relevance of the content to the target audience;

- scientific validity of the provided material;

- the optimal choice of environment (means) for the technical implementation of the project.

The criteria for evaluating projects and determining the winners of the face-to-face stage included additional points in the evaluation sheet:

- team approach to project development, inclusion of specialists in the field of digital technologies and subject areas in the team;

- possession of digital, presentation technologies and knowledge of the subject area when presenting a project.

Upon completion of the face-to-face stage, an anonymous survey was conducted in the form of feedback, during which an idea of satisfaction or dissatisfaction with the work of the educational platform was obtained. The feedback questionnaire included a description of the assessment of the content of the educational program of experts, the conditions of the educational program; comments of participants on the content of the educational program, the work of experts, the conditions of the educational program; information about the listener - participant of the hackathon, indicating his contact information for further interaction (optional).

Thus, the goal of the hackathon was to create an innovative platform that schoolchildren, students and young teachers can use in a practical way. Thanks to an approach that combined direct instruction on the use of IT technology in the process of research and project activities in history and local lore, the participants were able to master critical thinking skills (reflected in self-assessment, summary essays and group discussions), operational thinking skills, presentation skills, working with different software, prototyping websites and distributing their work. Today it is not only academic skills, but also professional competencies that are essential for personal development.

The quantitative results of the "My Russia" hackathon project are:

- 200 participants;

- 30 projects;

- information coverage - at least 10,000 people.

The best projects were: "Cultural Album: an electronic guide for preparing to the state final exam on History", "3D Model of the silver smelting factory", the project of the museum website "Living antiquity of village Berezovka", the project of a virtual quiz on the Mine Craft platform on history, the project of a computer game in Cold War setting, etc. 
The qualitative results following the project implementation were as follows:

- implementation of a new format of an educational platform with an output to a specific result - up to 30 new educational digital products (ideas, projects) in history and local history;

- the formation of the competencies of schoolchildren, students and practicing teachers in the field of creating web resources on history and local history, the basics of promoting products of intellectual activity;

- creation of a new platform for self-realization of talented youth, realization of individual abilities, leadership qualities and organizational skills;

- assistance to the integration processes of formation of a youth volunteer community in the study of the history of the Motherland; formation of a professional community of high school students, students and young teachers.

\section{Conclusions}

The correspondence stage of the project allows to maximize the geography and the number of competitors. The format of the historical hackathon "My Russia" can be used at any level of the education system: from primary schools to higher educational institutions and Quantorium technology parks.

As a result of the project, the digital educational platform "My Russia" begins to work, with the possibility of replenishing with new ready-made project products due to the specialized historical and local history events held at different levels of the education system.

This will ensure the viability of the project and the organization in the future of new extramural and face-to-face events with a variety of funding sources. The possibility of self-sufficiency of the educational platform is not excluded.

Summing up, it is necessary to emphasize the main methodological aspects of organizing a hackathon as an educational platform of a new format.

First, educational platforms of a new format, creatively using communication skills, information technology and software, should have a solid built-in learning component that allows schoolchildren, students and young teachers to become more confident in using IT technologies in the process of research and project activities in history. and local history and, therefore, focus on achieving meaningful practical results.

Secondly, in order to consolidate the skills of communication experience between the participants, the working groups formed on the educational platform, for the further development of the acquired skills, can remain active after the end of the hackathon. An element of preservation and involvement in active interaction between team members was the tutor and volunteer corps, which allows them to form self-management skills (managing emotions, energy, initiative, reflection, using feedback), which helped to effectively control their condition during the event.

Third, it is important to select educational and other informational materials not only with an emphasis on their relevance and relevance to a specific topic, but also to more effectively link them to practical tasks. So, for example, the body of experts included representatives of local history and search areas, IT-sphere, the basics of educational and project activities, specialists in the field of education management. The involvement of experts from the listed areas made it possible to minimize the knowledge gaps of participants on the hackathon topic and make the assessment of projects more objective.

It is also important to provide schoolchildren, students, young teachers with a space in which they feel safe, can control their actions, enjoy working together and feel that their work matters. For this purpose, the educational sites of the hackathon were equipped with information teaching aids, the practical activities of the participants were accompanied by 
tutor and volunteer support. This created a common situation of success for all project participants.

Thus, the main purpose of using the hackathon in the educational process is to create an interactive environment that contributes to the development of critical thinking, the ability to independently make decisions, communication and presentation skills in schoolchildren, students and young teachers. Today it is not only significant academic skills and abilities, but also professional competencies that are important in the development of personality [15, p. 45.].

\section{References}

1. The concept of long-term socio-economic development of the Russian Federation for the period until 2020, Russian Federation, access mode: http://www.consultant.ru/document/cons_doc_LAW_82134/28c7f9e359e8af09d7244 d8033c66928fa27e527

2. National project «Education», Russian Federation, access mode: https://edu.gov.ru/national-project

3. "Hackathon - 2019": students of the Pedagogical University are among the winners of the IT competition, Russian Federation, access mode: https://barnaul.bezformata.com/listnews/hackathon-2019-studentipeduniversiteta/74965910/

4. A. Vizgaleva, Legacy of the past and future technologies: the first historical hackathon "My Russia" of the Siberian Federal District, Russian Federation, access mode: https://old.altspu.ru/vospit/vospit_projects/hackathon_my_russia/29947nasledie-proshlogo-i-tehnologii-buduschego-pervyy-istoriko-patrioticheskiy-hakatonmoya-rossiya-sibfo.html

5. S.N. Batsunov, I.I. Derech, I.M. Kungurova, Modern determinants of soft skills development, Concept: scientific and methodological electronic journal, 4, 198-207 (2018)

6. A.A. Vasiliev, Project education as a technology for the development of creative cognitive activity of students, Forum of Youth Science, 3, 3-6 (2020)

7. D. Goleman, Emotional intelligence, p. 480 (Moscow, 2009)

8. D. Goleman, R. Boyatsis, E. Makki, Emotional leadership: the art of managing people based on emotional intelligence, p. 301 (Moscow, 2008)

9. Oxford English Dictionary, 2nd edition, p. 624 (Oxford: Clarendon Press, 1989)

10. I.I. Makarova, D.A. Kondakova, Problems of social and humanitarian education at the present stage of modernization of the Russian school: materials of the seventh international scientific and practical conference. - Konf., Barnaul, p. 228 (December 14, 2018)

11. A.V. Malanicheva, D.V. Ratnikova, World of Science, Culture, Education, 3, 343-344 (Gorno-Altaysk, 2019)

12. A.Sh. Bakmaev, Sh.A. Bakmaev, R.K. Paizulaeva, World of Science, Culture, Education, 6, 201-204 (2017)

13. E.F. Zeer, Psychology of professional development, p. 239 (Moscow: Academy, 2007)

14. A.A. Ignatenko, Problems of social and humanitarian education at the present stage of modernization of the Russian school, Materials of the sixth international scientific and practical conference, Conf., Barnaul, 151 (November 1, 2017) 
15. M.V. Korotkova, Science and School, 1, 153-156 (2017)

16. V.V. Pshenichnaya, E.R. Korotkevich, Educational resources and technologies, 1, 4147 (2019)

17. O.F. Bryksina, E.P. Krupoderova, Bulletin of the Minsk University, 1, 7 (2017)

18. S.A. Chernov, Humanitarian of the South of Russia, 5, 242 (2018) 